\title{
THE TA CONSULTANT PROGRAM
}

\author{
IMPROVING UNDERGRADUATE INSTRUCTION AND \\ GRADUATE STUDENT PROFESSIONAL DEVELOPMENT
}

\author{
Mikaela Huntzinger, University of Californa, Davis \\ Paul McPherron, Southern Illinois University, Carbondale \\ Madhumitha Rajagopal, Stanford University
}

Graduate students, particularly at research-oriented universities, are well prepared for future research careers, but they often lack knowledge or training in other aspects of academic life. A teaching assistant consultant program was created to improve the professional development opportunities for campus teaching assistants and provide a community of practice in which graduate students pursue teaching interests, cross-disciplinary collaboration, and service. We offer recommendations for creating similar programs and conclude by recommending the development of communities of practice to create opportunities for graduate students to improve their teaching skills.

Many students enter graduate school with a focus on research and little thought to teaching or service as part of their graduate experience. While these students complete programs in their intended fields and have opportunities to continue on research paths within their disciplines, some decide to pursue careers in which teaching plays a central role. At the University of California, Davis (UC Davis), the teaching assistant consultant (TAC) program has served as a catalyst and key experience in the process of teaching skills development.

The original intention of the TAC program was not to transform its participants; rather, the goal was more concrete to provide cost-effective professional development opportunities for graduate teaching assistants (TAs) campuswide by providing extensive services, from workshops to 
individual consultations. However, in our experience and that of many TAC fellows, the program also provides a space in which fellows can explore their developing teaching identities. With these twin functions, the TAC program is both an efficient means of providing teaching development opportunities for campus graduate students and a dynamic community of practice (COP) (Wenger, 1998) for its fellows.

\section{Graduate Student Development Programs and Communities of Practice}

In recent years, numerous reports, surveys, and research have documented the inadequacy of graduate programs in preparing graduate students for future careers (Association of American Universities, 1998; Austin, 2002; Bellows \& Weissinger, 2005; Berberet, 2008; Fleet et al., 2006; Golde \& Dore, 2001; Lovitts, 2001). Austin and Barnes (2005) note that graduate education programs send mixed messages about work and expectations in academic life by focusing on research training despite the reality that many graduate students will pursue and thrive in careers that involve large amounts of teaching and service work both inside and outside academe.

There are many potential ways to respond to this discrepancy between graduate training and work expectations following graduate study, including creating more opportunities for graduate students to participate in community service and learn about ways in which they can serve the public good (Austin \& Barnes, 2005; Golde \& Dore, 2001). UC Davis has responded to the dilemma by enlisting advanced graduate students to meet the campus's extensive demand for teaching development opportunities for graduate TAs in a way that has been as profitable for the participants as it has been for the campus as a whole. In general, group collaboration, which promotes the development of professional identities as members of academic communities, appears to be an effective and transformative tool that can profitably serve as the central element of graduate student professional development programs (Richlin \& Essington, 2004; Viskovic, 2006). More specifically, we view the TAC program as a COP in which participants are shaped through their collaboration and in turn shape the practices of the group or community, as described in Wenger (1998):

Being alive as human beings means that we are constantly engaged in the pursuit of enterprises of all kinds. ... As we define these enterprises and engage in their pursuit together, we interact with each other and with the world and we tune our relations with each other and 
with the world accordingly. In other words, we learn. Over time, this collective learning results in practices that reflect both the pursuit of our personal enterprises and collective social relations. These practices are thus the property of a kind of community created over time by the sustained pursuit of a shared enterprise. It makes sense, therefore to call these kinds of communities communities of practice. (original emphasis, p. 45)

Two key aspects of COPs are relevant to the TAC program. First, participants and leaders must seek a continual balance between personal enterprises and social relations, both of which influence and shape the knowledge and practices of the group. A COP is not a collection of passive individuals merely providing a service; a COP must emphasize action and shared knowledge formation (Ramanathan, 2002; Wenger, McDermott, \& Snyder, 2002). Second, the shared knowledge produced in COPs varies from "hard" knowledge, such as policy and institutional structures, to more qualitative "soft" knowledge that takes the form of best practices or common sense and is shared through stories and personal experience. The TAC program model is an effective way to offer graduate students from across campus better access to professional development, as implied in the findings of Golde and Dore (2001), Austin and Barnes (2005), and Bellows and Weissinger (2005), and it simultaneously creates a COP for the fellows in the program.

\section{The UC Davis TAC Program}

UC Davis, a large research-oriented university, has approximately twentyfive thousand undergraduate students and over seven thousand graduate and professional students. The TAC program is housed in the teaching resources center (TRC), which administers all campuswide faculty and graduate student teaching programs and provides grants for undergraduate course development. Although the center's budget has dropped in recent years and both programs and positions have been cut, the TRC has chosen to continue to fund the TAC program, based on its cost-effectiveness and impact.

The TAC program was established in 1996 to motivate and prepare incoming TAs and to develop resources for TAs' ongoing skill development. Eight to ten graduate students with significant teaching experience participate in the program yearly. One experienced TAC serves as the program coordinator, and an administrator from the TRC serves as the program mentor and "institutional memory." The graduate students in the program work together throughout the academic year, and 
their time is spent facilitating the annual campuswide TA orientation, offering one-on-one peer consultations with TAs, developing workshops and other resources for TAs, and meeting weekly in their group. Appendix $18 \mathrm{~A}$ provides an overview of the annual cycle of meeting agendas.

\section{TA Orientation}

The first event a new cohort of TACs prepares is the fall TA orientation for the approximately six hundred incoming TAs from about seventy-five departments on campus. The TACs work in teams to develop interactive three-hour workshops for approximately fifty incoming TAs at a time. Over the course of six meetings, the group develops a skeleton master lesson plan for their cohort, which is personalized by each team, and discusses which professional attitudes they want to convey to the incoming TAs, such as emphasizing student-centered learning and keeping reflective records of teaching experiences over time (see Appendix 18B). The TAC coordinator and the mentor lead this training period.

The fact that TA orientation is conducted largely by peer instructors (the TACs) is popular with both the incoming teaching assistants and the TACs. The evaluations received by the TAC presenters during orientation are consistently higher than those received by other presenters (unpublished data).

\section{Consultations}

After TA orientation, the TACs develop their skills as consultants during the first several weeks of fall quarter (Appendix 18A). TACs learn the format of and the skills necessary to complete three main types of consultations: midquarter interviews, also known as small group instructional diagnoses (Creed, 1997); videotaping; and classroom observations. TACs examine mock midquarter interview data to practice interpreting them, review teaching videos to consider how to respond to different teaching styles, discuss how to set TAs at ease during consultations, use skits to practice listening for subtext in interpersonal interactions, and play games to explore ways in which they can offer more useful feedback. TACs have conducted 1,524 individualized consultations in the thirteen years since the program was established (Table 18.1).

Consultations provide TAs with an opportunity to gain another view of their classroom and share their opinions and concerns about teaching with a peer consultant (Ballantyne, Hughes, \& Mylonas, 2002), and TACs with the opportunity to develop their mentoring and communication skills. 
Table I 8.I One-on-One Consultations Performed by the TACs for UC Davis Graduate Student Instructors

$\begin{array}{llll} & \text { Videotaping } & \begin{array}{l}\text { Midquarter } \\ \text { Interviews }\end{array} & \begin{array}{l}\text { Classroom } \\ \text { Observations }\end{array} \\ \text { Academic years TACs } & 1996-1997 \text { to } & 1996-1997 \text { to } & 2002-2003 \text { to } \\ \text { have provided this service } & 2008-2009 & 2008-2009 & 2008-2009 \\ \text { Total number provided } & 844 & 655 & 25 \\ \text { Mean per year (1 SE) } & 64.9 \pm 4.3 & 50.4 \pm 7.2 & 3.6 \pm 1.7\end{array}$

\section{Workshops}

After TACs have learned to perform consultations, much of the rest of the year is spent developing workshops (Table 18.2). During the winter quarter of the fellowship, TACs offer three to five workshops on either independent or interdependent teaching topics, and in the spring quarter, TACs offer a certificate-bearing series of six to nine workshops with a single theme. Workshops are highly interactive and rely heavily on small group activities. Participants who attend most or all of the workshops and submit the required assignment (usually a draft statement of teaching philosophy) earn a certificate of completion to put on their curriculum vitae.

The goals of the winter quarter workshops are to allow the TACs to "get their feet wet" with professional development workshops and to offer TAs the chance to learn something about a few specialized topics. To prepare these workshops, TACs split into teams, and each team develops a single workshop. The goals of the spring quarter workshop series are to give TACs the opportunity to teach an entire course for their peers and allow TA participants to explore a single topic in significant depth. Because TACs must work together to create the structure and content of the workshops, this part of the program fosters the type of group collaboration and exploration of identity implied in the notion of a COP. It also requires TACs to work on more practical aspects of group collaboration, such as prioritizing tasks and problem solving.

Table 1 8.2 Workshops Offered from 1996-1997 to 2008-2009 Academic Years

\section{Workshops Offered}

Total number

Mean per year $( \pm S E)$
242

$18.6 \pm 2.2$
Individual Attendances

3140

$241.5 \pm 24.7$ 


\section{Weekly Meetings}

In academia, where research, teaching duties, and other responsibilities weigh heavily on graduate students, it would not be surprising to hear that the fellows allowed the year to slip by without producing significant amounts of work. Yet the TAC program reliably produces many opportunities for individual teaching consultations and participation in teaching workshops for TAs. Research on COPs suggests that this productivity stems from the space the TAC program provides for the fellows to develop their commitment to each other and to their domain of improved teaching (Wenger, 1998; Wenger et al., 2002).

The space, the heart of this COP, is a mandatory two-hour meeting that occurs weekly throughout the academic year. This component inevitably raises eyebrows from many academics unfamiliar with COPs. Busy academics often suggest that they do not want to attend administrative meetings, much less such long and frequently scheduled ones. However, the nearly unanimous view of the individual TACs is that this program could not provide the benefits it does without the weekly meetings. In fact, at the suggestion of an outside reviewer of the group, the TACs recently debated meeting every other week or once a month in order to release their time for other TAC-related activities (they are required to invest an average of six hours per week). However, the TACs decided that despite their busy schedules, they needed the weekly meetings to develop priorities and to get and give feedback. They said that investing two hours per week doing work together was what gave them the motivation and direction to work on their own during the rest of the week. A recent TAC summarizes the value that weekly meetings hold for the TACs:

The experiences that most stand out for me from my time as a TAC are all related to the sense of community our cohort had. I remember one person saying that he liked coming to the TAC meetings because it was like a 12-step program-we were in a group where we didn't have to be ashamed that we cared about teaching. We all laughed.... Maybe my sharpest memory though was developing the first workshop in a small group (three TACs). I remember being surprised and delighted that all three of us actually showed up at the meeting place, ready to work and full of ideas. Until then, grad school had seemed like a place where everyone worked alone and in a funk. But the three of us were excited and happy to be working on this project that wasn't even required by our dissertation committees! Graduate school was very isolating for me, but my cohort of TACs offered me a place to connect. (TAC, 2004-2006) 
Although each weekly meeting is different, the components generally remain the same: development of upcoming events and materials, a professional development discussion, and logistics. As a rule, nearly half the time is spent working in small groups to develop upcoming events and materials, nearly half having a professional development discussion, and only a few moments covering logistics. The mood established by the leaders is, ideally, professional but lighthearted, well organized but flexible to respond to group interests.

TACs report feeling a sense of community in the weekly meetings that they often do not feel in their home departments or laboratories. For example, a former TAC describes this "safe" place when narrating her memories of the first TAC meeting:

In the first meeting, we were talking about something (I can't remember what anymore), and [a TAC] said, "I disagree with that." Everyone faced [the TAC]. There was a small beat of silence. [The group leader] voiced the natural一yet for me powerful—question, "What makes you disagree?" As I glanced around the table, it seemed that everyone's expressions mirrored how I felt at that moment: we were genuinely interested in why [the TAC] disagreed, that there should always be space at this table to acknowledge and incorporate dissent, that we are here to build a collective body of wisdom, experience, and knowledge that arises from understanding everyone's perspective to our utmost ability. I've carried this philosophy with me to every team that I've worked with since this moment. It was in these moments that I came to believe-in a visceral rather than purely intellectual waythat collective attainment (of knowledge, of a practice, ...) requires everyone to perceive that their ideas are legitimate. In terms of how a team forms a plan for the work ahead of them, "legitimate" doesn't necessarily mean ultimately correct; I mean that all ideas will be given a fair shake on the way to our individual conclusions at the end of the day, and on the way to the collective plan. (TAC, 2006-2008)

In our view, the weekly TAC meeting not only provides TACs with direction, but it also provides an opportunity for TACs to transform their understanding of teaching and learning. The group discussions that follow the reading of pedagogical articles encourage them to grapple with ideas and think creatively about incorporating different approaches into their own teaching. Ultimately the members of each group discuss their ideas in such depth that they tend to discover that group members share an understanding of teaching and learning that they have not read in any one document; that is, they cocreate knowledge. 


\section{Requirements and Recommendations for Program Success}

Creating and maintaining a successful TAC Program requires resources that include space, funding, and people. Space requirements include a consultation room and a meeting room. Funding requirements include fellowship stipends, salaries, and equipment funds. Each TAC receives a yearly fellowship of three thousand dollars, increments of which are distributed monthly during the academic year. The TAC coordinator receives a 50 percent graduate student researcher salary and does not receive the fellowship. In addition, one full-time staff member dedicates approximately a third of her time to serving as the mentor to the TAC program. Despite these costs, the TAC program is still more cost-effective than hiring one and a half to two full-time-equivalent staff members, the number we estimate would be required to provide services currently offered by the TACs (running the TA orientation, developing two workshop series, and doing over a hundred individual consultations each year).

While space and funding are difficult to acquire, we find that the human resources required of a high-functioning COP such as the TAC program may be the most difficult to develop. This program, which seeks not only to serve as a community for its members but also to produce products for other instructors on campus, requires many different individuals to sustain effort several hours a week throughout the academic year. We have found that a lapse in attention or commitment to the program by almost any member may be accompanied by a lapse in energy and output on the part of the entire group, and because graduate students have their attention pulled in many directions, we find this to be a significant threat.

Wenger and others (2002) note that COPs should "combine familiarity and excitement" and "open a dialogue between inside and outside perspectives" (p. 51). We add four additional suggestions for helping a TAC program to succeed: focus on buy-in from the first group meeting, maintain a safe space for open-ended discussion and play, maintain group knowledge (both hard and soft) while encouraging revision and cocreation of new practices and knowledge, and respond to varying needs of individual TACs, who represent different personality types, have different professional interests, and thrive with different types of mentoring.

Similar to other research on COPs, these suggestions emphasize the importance of authentic group collaboration and participation in the cocreation of knowledge and practice by creating safe spaces such as the weekly meetings (Richlin \& Essington, 2004; Viskovic, 2006). This balance between a familiar structure (including the established structures of the TA orientation and the topics of weekly meeting in the first quarter) and the excitement of embarking on creative projects and discussion 
(often leading to new workshops and interdepartmental collaboration) brings up the inherent tension in COPs between continuity and creativity. In establishing a lesson plan for the TA orientation and mapping out the process of training new fellows, the TAC program can ensure a certain degree of similarity in services from year to year. However, this uniformity has the potential to silence or dominate group discussion, particularly in the fall quarter. The TAC coordinator and mentor must be careful not to allow past practices or the interests, backgrounds, or personality types of individual fellows to dictate group practices. In other words, the TAC program is not static. The description and analysis in this chapter give a generalized view of the program, but we have found that it evolves constantly, which keeps it stimulating for the mentor and TACs who return for a second year.

The interplay of creativity and continuity highlights the role of power and power dynamics within the TAC model. Recent critiques of Wenger (1998) have noted that little attention is placed on how power is negotiated within a COP and how authority is used to achieve goals (Fox, 2000; Roberts, 2006). In our roles as TAC coordinators and mentors, we have seen certain power and control issues threaten to overwhelm the group, including the composition of project teams; the division of work among TACs; debates over lecturing, multiple-choice exams, and project learning; and the perceived dominance of TACs with previous knowledge and research in teaching and education. These issues and others are not insurmountable, but they do require constant attention and dialogue among fellows, and at times they require the creation of new TAC policy and the attention of TRC and university administrators.

\section{Concluding and Looking Forward}

The TAC program fosters the creation of collaborative COPs and may be transferable to a range of groups and interactions on a variety of university campuses. For example, a former TAC suggests the versatility of the COP model in emphasizing the process over the content area of the program:

No single project or experience stands out for me. This is because the power of the program rested in the people participating in it with me. Being in the company of fellow TAs and teachers that were passionate about teaching was inspiring. Not only was that passion contagious, but each member brought their own background, orientation, and strengths to the table. I most remember feeling "opened up" by others' viewpoints while we were engaged in some project. This opening was, for me, one of the most valuable effects of the program. I didn't 
leave the program with a grab bag of tips and tricks. I left with a new orientation to teaching and learning. (TAC, 2005-2007)

The TAC program is not unique in its idea of TAs helping TAs; similar programs can be found at many other universities around the United States. Universities structure their programs in unique ways to fit institutional needs, and further investigation of TAC-like programs across the country could explore the efficacy of TAC models and compare the personal stories of TACs. Questions to guide this comparison could include: Are all TAC programs focused, as at UC Davis, on creating a student-run COP, or do other effective models exist? In those identified as COPs, how are power dynamics managed? From a survey of different TAC programs, it appears that almost all programs are located at large research institutions that have well-funded teaching centers. Smaller public universities have generally not invested in TAC-like programs, and a further area of research could be to explore the reasons for this and explore alternative models of TAC programs that do not require significant financial investment.

In an era of ever-tightening budgets and with pressure to prove the worth of programs through assessment and quantitative increases in services, we hope that the TAC model at UC Davis can continue to provide needed services (demonstrating its institutional worth) as well as the freedom and space for professional development (demonstrating its personal worth to participants). We therefore join others (Richlin \& Essington, 2004; Viskovic, 2006) in advocating developing and maintaining TAClike programs. We find that the TAC program is a relatively inexpensive way to create many opportunities for graduate students to improve their teaching skills, either as TACs themselves or as participants in the many programs offered by the TACs.

\section{Appendix 18A: Annual Cycle of TAC Program Meeting Agendas Orientation}

\section{Late Summer}

\begin{tabular}{ll}
\hline Day & Topics \\
\hline 1 & $\begin{array}{l}\text { Overview of TAC program } \\
\text { Professional development (PD): What is good teaching? } \\
\text { PD: What do we know about new TAs? }\end{array}$ \\
& PD: Brief overview of five topics of the TA orientation (getting \\
started as a TA, promoting student participation, presenting \\
information clearly, grading efficiently and effectively, ethics) \\
Group review of past TA orientation master lesson plan
\end{tabular}


PD: Getting started as a TA

TA Orientation practice

4

PD: Promoting student participation

PD: Presenting information clearly

TA orientation practice

PD: Grading efficiently and effectively

TA orientation practice

Dress rehearsal for TA orientation

Note: Each meeting lasts three hours.

\section{Fall Quarter}

\begin{tabular}{|c|c|}
\hline Week & Topics \\
\hline 1 & $\begin{array}{l}\text { TA orientation review of evaluations and debriefing } \\
\text { TAC goals for year } \\
\text { PD: What is consulting? }\end{array}$ \\
\hline 2 & $\begin{array}{l}\text { Big picture of TAC year } \\
\text { PD: What is good teaching? } \\
\text { PD: What is improved teaching? }\end{array}$ \\
\hline 3 & $\begin{array}{l}\text { How to do a midquarter interview } \\
\text { Practice interpreting MQI results } \\
\text { PD: Principles for good practice in higher education }\end{array}$ \\
\hline 4 & $\begin{array}{l}\text { Role play: Midquarter interview consultation } \\
\text { How to do a videotaping } \\
\text { PD: Watching yourself on videotape }\end{array}$ \\
\hline 5 & $\begin{array}{l}\text { Watch video playback consultation } \\
\text { Role play: video playback } \\
\text { How to do classroom observations }\end{array}$ \\
\hline 6 & $\begin{array}{l}\text { Consultation skills wrap-up } \\
\text { Brainstorm for winter quarter workshop series }\end{array}$ \\
\hline 7 & $\begin{array}{l}\text { Winter quarter workshop series-products this week and next: } \\
\text { Titles and advertising blurbs } \\
\text { General goals for each workshop } \\
\text { Dates and times } \\
\text { Team members for each workshop } \\
\text { PD: Promoting teaching through experiential workshops }\end{array}$ \\
\hline 8 & $\begin{array}{l}\text { Unfinished workshop tasks from last week } \\
\text { PD: Learning in workshop settings }\end{array}$ \\
\hline 9 & $\begin{array}{l}\text { Small group work on winter quarter workshops } \\
\text { Fall quarter wrap-up }\end{array}$ \\
\hline
\end{tabular}

Note: Each meeting lasts two hours. 


\section{Winter Quarter}

\begin{tabular}{|c|c|}
\hline Week & Topics \\
\hline 1 & Practice workshop 1-do a complete dry run \\
\hline 2 & $\begin{array}{l}\text { Practice workshop } 1 \text { again if necessary until team is confident, or } \\
\text { begin planning for spring workshop series }\end{array}$ \\
\hline 3 & Practice workshop 2 \\
\hline 4 & Practice workshop 2 again if necessary \\
\hline 5 & Practice workshop 3 \\
\hline 6 & Practice workshop 3 if necessary or Workshop 4 if it exists \\
\hline 7 & $\begin{array}{l}\text { Spring workshop series planning--products this week and next: } \\
\text { Titles and advertising blurbs } \\
\text { General goals for each workshop } \\
\text { Dates and times } \\
\text { Team members for each workshop }\end{array}$ \\
\hline 8 & Unfinished workshop tasks from last week \\
\hline 9 & Practice workshop 1 of spring workshop series \\
\hline
\end{tabular}

Note: Each meeting lasts two hours. All professional development for winter quarter is decided by the TACs themselves. Each person takes one day and chooses his or her own teaching article to discuss with the group.

\section{Spring Quarter}

Each meeting lasts two hours. All professional development for spring quarter is decided by the TACs themselves. Each week the TACs practice the upcoming week's workshop, troubleshooting and revising where necessary. The final week is spent as a cross-over meeting where the incoming cohort is invited to meet and talk with the outgoing cohort.

\section{Appendix 18B: TA Orientation Master Lesson Plan}

Following is one version of the skeleton master lesson plan for one threehour TA orientation workshop. This master was developed from previous cohorts' master lesson plans. The incoming TAC group also suggests interactive activities for each topic in the lesson plan. For example, we have accumulated five scenarios for the "Dealing Ethically" section.

\section{TA Orientation Session Outline}

- Introduction

- The First Day

- Setting the atmosphere 
- The Rest of the Quarter

- Doing clear presentations

- Generating discussion and student involvement

[Break]

- Grading student work

- Dealing Ethically with Students, Colleagues, and Professors

- Open question period

- Preparing for the future

- Summary and conclusion

- Evaluations

\section{REFERENCES}

Association of American Universities. (1998). Committee on graduate education report and recommendations [Press release]. Retrieved from www.aau .edu/publications/reports.aspx?id $=6900$

Austin, A. (2002). Preparing the next generation of faculty: Graduate school as socialization to the academic career. Journal of Higher Education, Special Issue: The Faculty in the New Millennium, 73(1), 94-122.

Austin, A., \& Barnes, B. J. (2005). Preparing doctoral students for faculty careers that contribute to the public good. In A. J. Kezar, T. C. Chambers, \& J. C. Burkhardt (Eds.), Higher education for the public good: Emerging voices from a national movement (pp. 272-292). San Francisco: Jossey-Bass.

Ballantyne, R., Hughes, K., \& Mylonas, A. (2002). Developing procedures for implementing peer assessment in large classes using an action research process. Assessment and Evaluation in Higher Education, 27(5), 427-441.

Bellows, L., \& Weissinger, E. (2005). Assessing the academic and professional needs of graduate students. In S. Chadwick-Blossey \& D. R. Robertson (Eds.), To improve the academy: Vol. 23. Resources for faculty, instructional, and organizational development (pp. 267-281). San Francisco: Jossey-Bass/Anker.

Berberet, J. (2008). Perceptions of early career faculty: Managing the transition from graduate school to the professorial career. TIAA-CREF Institute: Research Dialogue 92. Retrieved from www.tiaa-crefinstitute.org/ articles/92.html

Creed, T. (1997). Small group instructional diagnosis (SGID) [supplementary materials]. National Teaching and Learning Forum, 6(4). Retrieved from www.ntlf.com/html/pi/9705/sgid.htm 
Fleet, C. M., Rosser, M.F.N., Zufall, R. A., Pratt, M. C., Feldman, T. S., \& Lemons, P. (2006). Hiring criteria in biology departments of academic institutions. Bioscience, 56(5), 430-436.

Fox, S. (2000). Communities of practice: Foucault and actor-network theory. Journal of Management Studies, 37(6), 853-867.

Golde, C. M., \& Dore, T. M. (2001). At cross purposes: What the experiences of doctoral students reveal about doctoral education. Retrieved from www.phd-survey,org/

Lovitts, B. E. (2001). Leaving the ivory tower: The causes and consequences of departure from doctoral study. Lanham, MD: Rowan \& Littlefield.

Ramanathan, V. (2002). The politics of TESOL education: Writing, knowledge, critical pedagogy. New York: RoutledgeFalmer.

Richlin, L., \& Essington, A. (2004). Faculty learning communities for preparing future faculty. In M. D. Cox \& L. Richlin (Eds.), New directions for teaching and learning: No. 97. Building faculty learning communities (pp. 149-157). San Francisco: Jossey-Bass.

Roberts, J. (2006). Limits to communities of practice. Journal of Management Studies, 43(3), 623-639.

Viskovic, A. (2006). Becoming a tertiary teacher: Learning in communities of practice. Higher Education Research and Development, 25(4), 323-339.

Wenger, E. (1998). Communities of practice: Learning, meaning, and identity. New York: Cambridge University Press.

Wenger, E., McDermott, R., \& Snyder, W. M. (2002). Cultivating communities of practice: A guide to managing knowledge. Boston: Harvard Business School Press. 